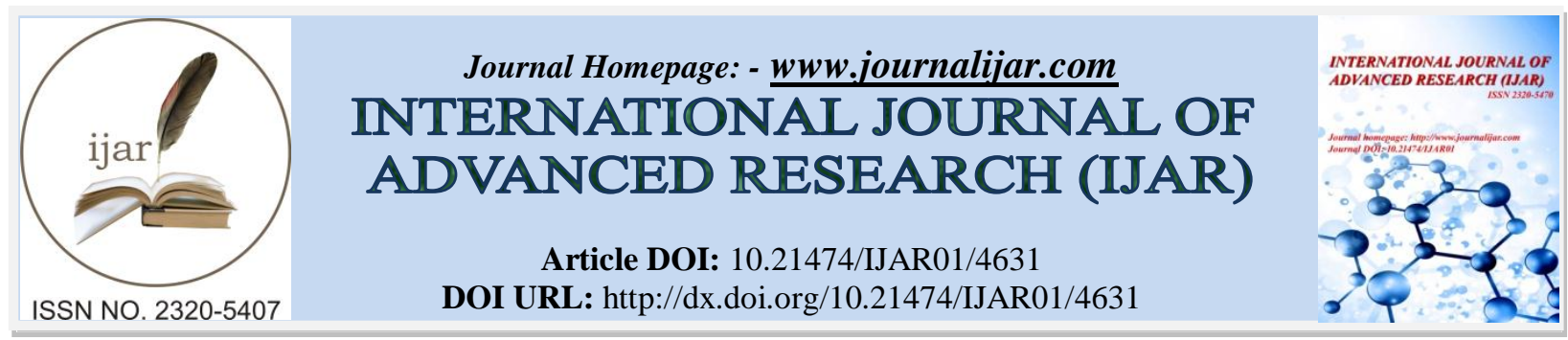

RESEARCH ARTICLE

\title{
CHALLENGES OF PROJECT MANAGEMENT ALIGNING TO THE PROCESS GROUPS THAT CAN FULFIL THE CLIENTS' EXPECTATIONS.
}

\author{
G. V. Bhanu Sai Prasad ${ }^{1}$, V. B. N. V Sai ${ }^{1}$ and Dr. Kiran Kumar Reddi ${ }^{2}$. \\ 1. Research Scholar, Rayalaseema university, Kurnool India. \\ 2. Department of Computer Science, Krishna University, Machilipatnam.
}

\section{Manuscript Info}

Manuscript History

Received: 27 April 2017

Final Accepted: 29 May 2017

Published: June 2017

Key words:-

software Project management;

Customer; project manager; charter;

creativity; creep; confidence; culture; cross-functional; cohesiveness.

\begin{abstract}
In general, Project Manager masters the project management methods and processes. Upon to the dynamic changes in the projects, project management needs adaptability and willingness to deal the unexpected situations. Project Managers building these abilities can gain customer confidence and can fulfill the exact needs of the clients' expectations. In this paper the challenges are properly aligned to the process groups considering their impact. Project management if consider these challenges can fold the project delays and can manage the dynamic situations. With the recent trends and changes in the process, irrespective of the methods followed every project goes through the project management process groups. Project manager needs to chalk out or list out all the challenges such that (s) he being the project representative in the organization as well to the client, needs to make all the stake holders responsible to deliver a product or project which fulfill the exact needs of the client or customer. Project Manager is always surrounded by a plenty of challenges, where the challenges need prioritization by aligning them with the knowledge areas as well the process groups can yield more success to the overall project. Let's discuss here if project manager aligns the challenges to the respective process groups by strengthening the approach, can pave way to the success of the project and gain the customer confidence.
\end{abstract}

Copy Right, IJAR, 2017,. All rights reserved.

\section{Introduction:-}

Project manager stands at top in the project and project process groups starts from there. Whether a techie or nontechie project manager, unsuccessful stories can be heard if the stake holder engagement at right process groups is important. Success stories can be unfolded upon tactful engagement of resources and stake holders.

Most of the times, projects are calculated upon the completion of the project. May it completed in time or delayed. Success sometimes also says even if project is not completed. A question comes to every mind like, how is it possible? This is like the Project Manager and the stake holders followed the process and worked together to complete. Here Project management works on how successfully the project management methods are applied irrespective of the product launched with delay. Always when the process and project management methods applied properly as part of the project, the product goes to the customer which fulfills the customer needs. 
Here project manager is responsible in how to deal challenges and applying to the project management techniques appropriately. Why do we need project manager? When all the stake holders are responsible for a project delivery? Project manager drives the project, tracks the progress, defines the process to be followed by the stake holders, plan for resources, monitor and control the execution. All of them are defined to the project members or stake holders to follow for the successful completion of the project.

There are three most important elements in project management: quality, scope and cost. A so-called "triple constraint" is the main factor determining the quality and success of the project. They constrain to each other because the relationship between them is mutual in a sense that if there is any change on one of them, the rest will be affected.

Project management involves planning, scheduling and controlling all of the project activities to achieve its objectives. In other words, project management is the application of knowledge, skills, tools and techniques to project activities to meet project requirements. Project management is accomplished through the application and integration of the project management processes of initiating, planning, executing, monitoring, controlling and closing ((Duncan 2000, 8). The tasks of managing a project are limitless as operational practices; however, they can be summarized in these few key roles:

Every project differentiates itself by its uniqueness and the purpose of its existence. Therefore, requirements of the project need to be identified and analyzed clearly.

Objectives of a project need to be defined and need to be communicated to all team members. The objects should be achievable and need to be clear, in order for each of the team members to understand and implement efficiently.

\section{Role of Project Manager:-}

Project Management is often the responsibility of an individual project manager. The individual participates directly in the activities that produce the end result. Project manager strives to maintain the progress and also the mutual interaction and the tasks of various people/members by finding a way to reduce the risk of overall failure, and restricting costs, leading to maximize the benefits.

Most of the project management issues that influence a project arise from risk, which in turn arises from uncertainty. A successful project manager focuses on this as his/her main concern and attempts to mitigate risk significantly, often by adhering to a policy of open communication, ensuring that project participants can voice their opinions and concerns.

Project tools or techniques and knowledge are used for managing projects and are unique to Project Management.

\section{Extended Study On The Challenges:-}

This study is done mainly on the Tools and techniques that Project Manager can concentrate. Below are the mentioned challenges which are $20 \mathrm{C}$ 's. Understanding and applying the tools and techniques which are generally recognized as good practices are not sufficient alone for effective project management. Effective project management requires that the project manager understands and uses the knowledge and skills on the below technical/management challenges.

The literature on the study of the project manager challenges are detailed below.

\section{Customer:-}

Customer or Client is the most important person as far as project is considered. Project manger's first challenge is customer/client. To become an efficient project manager, streamlining of self is necessary and the focus needs to be on the following.

a. Engaging Customer as part of the team.

b. Planning at least one formal status call with Customer as well delivery team.

c. Formalizing weekly status reports.

d. Revisiting or managing the issues and risks often weekly upon availability of project time.

e. Communicate effectively, by keeping everyone in the project up to speed with both formal and informal (emails, phone calls, etc.) modes of communication 


\section{Concept:-}

Concept is one of the critical challenges being faced by the project manager in the Initiation phase. This is to evaluate the new idea on how the project is going to be.

A concept is an orderly and efficient approach to suggest, review and judging the merit of a new project idea prior to the significant resources are committed to the official project. And this is to ensure that resources get allocated only to worthwhile projects. This also helps in procurement of requirements and other resources.

\section{Charter:-}

What's a Project Charter?

This is also called as Project overview statement (POS), is the signed document that formally defines and authorizes a project. This is like reaching to an agreement, which includes scope, objectives and constraints.

Why a Project Charter is needed?

The Project charter keeps all the people involving in the project on the same page, such that the goals of the project are often understood correctly by the stake holders.

On a brief, the project charter contains the following

Project Authorization, Project Manager Authorization, Key Stake holders, Project Goals, Project Priorities, Scope statement, product requirements, project assumptions, project constraints \& boundaries, Initial project risks, list of deliverables, cost estimates, schedule estimates, integrated change control and success criteria.

\section{Clarity:-}

Why Clarity is needed?

Project manager has to define the goals clearly, if not entire team and project can suffer. Right questions are to be from the project manager to establish the goals and communicate to the team with added clarity.

Clarity is one of the challenges to be considered at all the process groups of the project management. Communication is the most important element to project success and yet it remains a challenge throughout the engagement. The information which is being propagated by a project manager needs to be clear and needs to dissolve weak links to soothe conflicts, to report status, and to revise the schedule.

\section{Creativity:-}

Why to bother about Creativity?

Creativity is a matter of survival and a must approach to grow and innovate. Organization that doesn't innovate inevitable ages and decline. 1

Creativity is the art of producing new ideas, approaches and actions. Creativity is a starting point for innovation. Starts with problem identification and ends with a creative idea.

A Project manager should overcome the two types of barriers to creativity

1. Personal Barriers

Beliefs and attitudes, taking life seriously, Time availability, thinking the self is not creative and comparing to others. Fear of failure.

2. Organizational Barriers

Risk avoidance, Change resistance, Leadership style, Group think, Lack of motivation

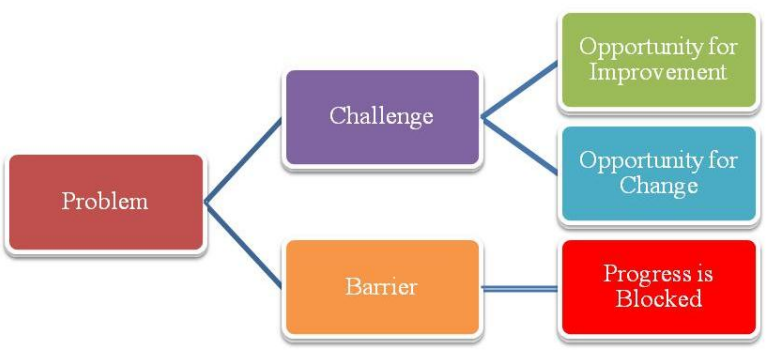

Figure 1:- Creative thinking Analysis. 
To overcome the barriers a project manager can be curious enough, persistent, have full of energy, self-motivated, open minded, risk taker and having diverse experience and social to others.

Creativity helps project manager for problem solving, improving process and final product as well services. It gives Quality and value to management as well helps in turning risk to opportunity.

\section{Cost:-}

Project managers are in a tough spot: They're the liaison between the customer and the project team that will complete the customer's project. In most organizations, it's generally easier to get more time than money, and there's usually more concern about how much than how long. Project managers and their stakeholders need to go into any project with a common goal: Identify an affordable scope and a plan of how to achieve it. Too often, and maybe because of the subject matter itself, cost is ignored in project planning. For projects to be successful, someone has to foot the bill, and until the estimate is requested or provided, it's not a mystery, just a constant dread.

If the customer demands new deliverables in the project scope, however, a price tag is usually associated with those demands. When the project scope changes, the budget usually has to change as well. Changes generally cost something, and that means a budget increase.

\section{Creep:-}

When inexperienced project managers start on their first few projects they usually underestimate the power of scope creep to cause a project to fail. This is why knowing how to avoid scope creep is absolutely vital to a successful project management career and trying to implement the following points:

1. Write an accurate project scope statement

2. All the accurate project requirements are documented and approved.

3. Strictly enforce the change request process.

How to avoid Scope Creep?

Never forget what your project scope is. Everyone will continually try to get you to make seemingly "small" scope changes, which you should resist.

\section{Communication:-}

Communication is the most important element to project success and yet it remains a challenge throughout the engagement. Project manager has to communicate quickly and efficiently at all levels of business. The project manager must be a confident communicator and must be connected within the organization. The well-connected project manager can break down barriers and get critical tasks done for his projects that others cannot. Customers want and need a project manager who is ready to lead and make things happen and can work well with all levels within his own organization for the success of the projects he manages.

A common problem is managers get lost in translation of the requirements. Project Manager needs to ensure the requirements need to be very crisp which helps in avoiding the kind of miscommunication.

Clear communication in requirements always provides edge to the Project manager in handling mutli-dimensional and complex projects by overcoming the challenges.

\section{Competence:-}

What is competence?

A competent professional is generally understood to be someone who "can do the job."

What then is project management competence? What are the knowledge, skills, and attitude that project managers must possess?

It is generally agreed that the overall scope of competence covers these three areas.

1. Gaining Knowledge

2. Become skilled

3. Having the Right Attitude 
Knowledge consists of the general and specific project management theory, concepts, practices, procedures, processes, and methodologies that apply to an industry and the complexity of projects being conducted. The project manager must first possess knowledge of the technical aspects of the industry to an extent that he or she understands the product and service being built and delivered. The business aspects are typically described in project management literature that address schedule, cost, risk, and other functions that relate to the overall management of a project.

Skills are the application of knowledge to project work that ensures accomplishment of the work in an effective and efficient manner. The skill functions are those defined by the industry, project size, project complexity, and organizational perspective for projects. A project manager may not possess all the detailed skills for the project, but may rely on others to perform designated tasks.

Attitude is the personal and professional demeanor exhibited by a person while performing his or her work. In the context of competence, this would be a positive outlook and an ability to not take one's self too seriously. Attitude includes drive, energy, good instincts, and dedication. A project manager must demonstrate the correct attitude when working with all the project stakeholders, e.g., project team, senior management, customer, and special interest groups.

\section{Create/Charts:-}

Scheduling is based on experience and the more experience you have, the more accurate your schedule will be. However, you can still produce an accurate schedule by following some simple rules.

Never give off-the-cuff or unconsidered responses, i.e. don't commit to something you can't deliver. Eliminate uncertainty wherever you can. Build in plenty of contingency to cope with variation. Pick the right level of granularity. Schedule the unexpected.

Project management is the art of handling the unknown. Often events and circumstances you could not have foreseen will interrupt the flow of your project. It's your job to take them all in your stride. Schedule for the most likely delays and cope with them should they arise. If experience or instinct tells you that a certain type of task will overrun, then anticipate it, pad it with some contingency and make sure you have adequate resources on hand when it comes up.

\section{Complexity:-}

\section{A. What is Complexity?}

Project complexity is often recognized in a general way, but not completely understood by everyone. Just the term "Complexity" causes some degree of difficulty because of the different interpretations given the definition and perhaps a person's experiences and training. Exploring the fundamental meaning of "complex" is helpful in establishing a foundation from which to build. "Complex" comes from the Latin word complexes, meaning entwined or twisted together.

During execution project manager may be struggling with problem solving, discovered complexity can be overstated. Following project completion, some complexity challenges may be viewed in context from a more realistic point of view without the means to influence what happened.

Projects have two primary areas for complexity

Technical Complexity:-

Technical scope of the product and service may be viewed as creating a specification that leads to a design to meet the client's needs.

\section{Management Complexity:-}

Management complexity includes the business aspects of the project, staff, relationships of the project to others, and project organization to name a few. There are many variables that can add complexity to the management of a project. 


\section{Control:-}

\section{What is Project Control?}

The term control has several meanings. Those new to project management are initially dismayed by the use of the term "control," because they mistakenly equate it with the concept of authority. In the world of project management, control has very little to do with telling people what to do, dictating their actions or thoughts, or trying to force them to behave in a certain way- all of which are common interpretations of control.

It's about continually making course adjustments with one main objective in mind-bringing the ship into safe harbor, as promised at the start of the voyage. And the successful project voyage includes identifying a specific destination, carefully charting a course to get there, evaluating your location throughout the voyage, and keeping a watchful eye on what lies ahead.

Overall project control requires an eye on the future, as this formula shows:

Calculated Present Variance + Estimated Future Variance $=$ Final Project Variance

Maintaining proper control really requires that you consider three parameters: (a) where you are, compared with where you're supposed to be; (b) what lies ahead that can affect you; and (c) where you're going to end up, compared with where you said you would end up.

\section{What Are You Actually Controlling?}

* Schedule: Was the project completed on time? (How long did we take?)

* Cost: Did the project come in at cost? (How much did we spend?)

* Risk: Oftentimes, projects don’t go exactly as planned. Project manager need to know how to collect information, develop trust and anticipate the modules which are likely to fail.

The other two targets are tied to the deliverables of the project:

* Functionality: Do project deliverables have the expected capability? (What can they do?)

* Quality: Do the deliverables perform as well as promised? (How well can they do it?)

\section{Co-ordination:-}

A Software Project requires some level of coordination and some level of management. Project Coordination is generally informal and is performed by most project team members in the course of performing the daily project tasks. Most of the time Project coordination deals with the things that are not plan able and are too minor to be formally planned or most importantly with the unexpected.

The meaning of coordination is to ensure that the defined project objectives are met within the constraints of time and budget, and with the required level of quality.

Multi-dimensional and multi-layered projects need a lot of coordination, communicate the team for any re-organize to minimize dire consequences on projects

\section{Caution:-}

A caution is a technique part of project Management is to be considered when traversing from one phase to another. This is like when the work related to the present phase is completed and moving/shifting to the subsequent phase. What to Expect?

The Project manager needs to be cautious on what to expect from team members and vice-versa. Project Manager need to work with team to discuss the sufficiency of resources which is essential in successful completion of the project.

Reasonable deadlines : Always project manager has to work on deadlines and is to be cautious to be reasonable.

\section{Conflict:-}

Conflict in project management is inevitable. The potential for conflict in information systems development projects is usually high because it involves individuals from different backgrounds and orientations working together to complete a complex task. The cause of conflict in team projects can be related to differences in values, attitudes, needs, expectations, perceptions, resources, and personalities. Proper skills in dealing with conflict can assist project 
managers and other organization members to handle and effectively resolve conflicts which can lead to a more productive organization as a whole.

\section{Ripple effect?}

Most of the times Project manager works on similar type of projects. People, equipment, resources and deliverables are interrelated. These dependencies are to be properly planned or to be considered; if not a single project delay has a significant ripple effect on related projects by disrupting schedules on related projects. This results in disrupting schedules, causing resource conflicts.

\section{Bottle necks?}

Most of the projects are running with inadequate resources, and projects run in parallel. People are assigned concurrently to different projects at same time. There comes a high demand for the people with specialized expertise and scarce skills. Project manager has to plan accordingly like the resource conflicts are not causing bottle necks. Adding a supportive resource with the expert for important modules is to ensure the resource conflict not to become a major challenge.

Lesser the ripple effects and bottle necks, more the success stories unfold in the multi-dimensional projects.

\section{Critical thinking:-}

A source defines critical thinking as "the purposeful and reflective judgment about what to believe or what to do in response to observations, experience, verbal or written expressions or arguments"

Despite all the planning done, project managers are often plagued with a litany of uncertainties. Should a project manager be concerned about situations or circumstances in the future of the project that might not even happen? On the other hand, a complacent project manager might react diametrically opposite by "letting things happen and decide what to do when they do happens".

\section{Enemies of Project Management:-}

A project has so many unseen enemies. These enemies are not made from "flesh and blood". They are elements, actors and variables a project manager needs to consider and manage with prudency. Ignoring or by-passing they can be a recipe for disaster. Just what are the enemies of a project that a project manager need to seriously counter against?

\section{Assumptions:-}

These can be a project killer if assumptions turned invalid when validity is expected, or vice versa. In cases where invalid assumptions mean what you thought things would be made available but have turned out to be otherwise, this can mean risks are nearing.

Therefore, non-critical thinkers that allow assumptions to bypass without validation will likely suffer the consequences of ill-preparation.

\section{Benefits of Critical Thinking:-}

Critical thinking throws project managers and their teams into situations that may not have existed yet or have possibilities of occurrence.

Critical thinkers perch from the roof of the project to be more observant rather than ignorant of situations.

Critical thinkers allow grounds for debates or arguments by throwing light to a given inference.

\section{Change:-}

"It is always easier to talk about change than to make it".

Change is a technique which can be of technology change, Organizational change, Scope change, requirement change and so on. A Project manager should not be resistant to the change.

Changes to projects are almost inevitable. As project work progresses, discoveries are made, problems are encountered and solved, new requirements are discovered. All of these have the potential to change one or more of 
the three main constraints that bound any project -- Time (the deadline), Resources (the people, materials and money available to do the project), and Output (the required deliverables).

Any change that affects one of these constraints can seriously affect the ultimate delivery of the project. For instance, if the deadline is tightened, you will need more resources to deliver the same output. If the resources available are reduced (usually in the form of lost people), you will likely need more time to deliver the output. If the output requirements change (usually added functionality or features) you will need either more time or more resources.

When changes take place they should be properly documented.

* Who is requesting the change?

* What change are they asking to be made? (Must be documented in great detail)

* How important is this change?

* What impact will this change have on the project? (Time, Resources, Output)

- Does the client approveof the change to the project? (Time, Resources, Output)

* How will the existing project plan change to incorporate the change?

* Who is authorizing the change? Just because the person is requesting the change, doesn't mean they have the authority to approve the change. The project manager must get this request infront of the person with the authority to approve the changes.

\section{Culture/Cross-functional:-}

Cross-functional teams are significantly different from teams that are aligned on one functional level. For example, a group of marketing people generally "speak the same language," and they have a solid understanding of what their department is trying to accomplish. With a cross-functional team, you may have representatives from a wide array of specialties - finance, accounting, operations, legal, human resources - and each person has his or her own perspective and issues. This diversity is both the reason why cross-functional teams can be highly effective, but it's also the reason that they're often problematic.

\section{Leadership is Essential:-}

It's not enough to simply manage a cross-functional team - you must lead it. Strong leadership creates and fosters team unity, and that leadership is key to your success. Because of outside pressures, this type of team must have internal strength and commitment to survive. At the same time, the team leader has to know when and how to allow functional experts to take the lead. After all, when you bring together a group of highly talented people, many individuals within the team may know more about the problem - from their own perspective - than the team leader. This situation requires a careful leadership balance. Tasks must be tightly coordinated and organized, and yet people must be free to use their talents and expertise as needed.

\section{Cohesiveness:-}

Project manager can generally use the following five techniques or methods to keep my remote projects and teams running smoothly:

* Setup a communication plan from the start

* Use a collaborative PM tool

* Hold weekly internal team meetings

* Expect participation from each member on formal customer calls

* Meet for major phase kickoffs

What I want to do is discuss this chart as it relates to project management and from a positive point of view. Instead of looking at this from five dysfunctions, the author also listed 5 functions of a cohesive team. This consists of the following:

1. They trust one another.

2. They engage in unfiltered conflict around ideas.

3. They commit to decisions and plans of action.

4. They hold one another accountable for delivering against those plans.

5. They focus on the achievement of collective results. 


\section{Closure:-}

Project closure is the last phase of the project management process. The project process is completed and documented, and the finished product is transferred to the care and control of the owner. The long-term objective is to build a project management repository to document best practices, lessons learned, and examples of various documents that may be developed during a project.

Project management processes produce the following deliverables during the closing stage of the project life cycle:

Basic Project : Lessons Learned, Closing Report

Full Project : Lessons Learned, Closing Report

\section{Findings:-}

In this paper as mentioned, the challenges when are aligned to the project management process groups, convinced many of the managers and project management teams across different organizations. These challenges provoked thoughts in the management teams that what is missing in the projects day in and day out. The best finding of the survey is "Whatever project life cycle methods we follow either water-fall or agile, these challenges if considered can boost the confidence of the project management team",



Figure -2 : Challenges aligning to the process areas

A detailed questionnaire was presented to the multiple teams and management members, yielded positive responses supporting the consideration of the challenges.

The challenges post aligning to the PM process groups can be as mentioned below.

1. Initiation Phase - Customer, Concept, Charter, Clarity and Creative

2. Planning Phase - Cost, Creep of Scope, Competency and Communication

3. Execution Phase - Create/Charts, Complexity

4. Monitoring \& Control Phase - Control, Coordination, Caution, Conflict, Critical thinking, Change, Culture and Cohesiveness

5. Closure Phase - Complete.

Project manager must demonstrate the competence through on-the-job performance as validated by an independent assessment of qualifications. As project complexity increases, there is a greater need to look for simple solutions that work. Use complex solutions only when necessary and use them infrequently. By utilizing project management principles, understanding the dynamics of conflict, and learning approaches to conflict resolution, managers will be able to establish an environment in which creativity and innovation is encouraged and project goals are accomplished. Critical thinking project managers are those who consider themselves accountable for the project, as they are willing to take ownership of the success or failure of their projects 


\section{Conclusion:-}

Project Manager a sole and multitasker of small and simultaneous projects within the envelope of an overall project can distinguish the process groups for the multiple and overall project to the challenges mentioned. Project management or team can overcome the challenges ease to manage the stake holders and the project/s resulting improving success of the overall project and can gain the confidence and reach expectations of the client.

There is a scope of future work improving or extending these challenges or each to the individual challenges.

Aligning the challenges to the process groups improves the project management team abilities and adaptability to the technical and non-technical changes coming across in the overall project. And these challenges unfolds the success stories of the multiple projects and pave way to the success as well fulfill the exact needs of the client or reaching the exact client expectations.

\section{References:-}

1. Marcus T. Project management an introduction. URL:http://www.newgrange.org/FTP/pm.ppt

2. Teamworks. Project management. URL:http://www.vta.spcomm.uiuc.edu/PMT/pmt-ov.html

3. ISDP. What is project management? URL:http://itprojmngt.8m.net/projman/pm_what.html

4. Project Management Institute. Project management-a proven process for success. URL: http://www.pmi.org/projectmanagement/success.htm

5. TenStep Project Management Process. The value of project management. URL:http://www.tenstep.com/0.0.1\%20Home\%20-\%20Value.htm

6. Hoffer JA, George JF, Valacich JS. Managing the information systems project. In:Modern Systems Analysis \& Design. Upper Saddle River, NJ:Prentice Hall, 2002, pp 59-92

7. ISDP. Role description project manager. URL:http://itprojmngt.8m.net/projman/organization/functions/jd_project_manager.html

8. Ford J. Workplace conflict: facts and figures. URL:http://mediate.com/workplace/ford1.cfm

9. Ford J. The training of conflict resolution skills in the workplace. URL:http://www.mediate.com/workplace/workedit3.cfm

10. Capozzoli TK. Conflict resolution-a key ingredient in successful teams. Supervision (60:11), 1999, pp 14-16

11. Wall JA Jr, Callister RR. Conflict and its management. Journal of Management(21:3), 1995, pp 515-558

12. Dana D. What's a conflict? URL:http://www.mediate.com/articles/dana1.cfm

13. Klunk SW. Conflict and the dynamic organization. Hospital Materiel Management Quarterly (19:2), 1997, pp $37-44$

14. Teamworks. Using team conflicts. URL:http://www.vta.spcomm.uiuc.edu/TCT/tctl1-ov.html

15. Van Slyke EJ. Resolve conflict, boost creativity HRMagazine(44:12), 1999, pp 132-137

16. Cloke K, Goldsmith J. Conflict resolution that reaps great rewards. The Journal for Quality and Participation(23:3), 2000, pp 27-30

17. Lloyd SR. Conflict resolution: steering clear of the drama triangle. Rural Telecommunications(20:5), 2001, pp 30-34

18. Barnett E. Managing conflicts in systems development. Hospital Materiel Management Quarterly(18:4), 1997, pp 1-6

19. Kerzner H. Conflicts. In:Project Management: A Systems Approach to Planning, Scheduling, and Controlling. New York, NY:John Wiley \& Sons, 2001, pp 379-408

20. Friedman RA, Tidd ST, Currall SC, Tsai JC. What goes around comes around: the impact of personal conflict style on work. International Journal of Conflict Management(11:1), 2000, pp 32-55

21. Rahim MA, Manger NR, Shapiro DL. Do justice perceptions influence styles of handling conflict with supervisors?: what justice perceptions, precisely. International Journal of Conflict Management(11:1), 2000, pp 9-31

22. Barki H, Hartwick J. Interpersonal conflict and its management in information system development. MIS Quarterly(25:2), 2001, pp 195-225

23. Al-Tabtabai H, Alex AP, Aboualfotouh A. Conflict resolution using cognitive analysis approach. Project Management Journal(32:2), 2001, pp 4-16

24. http://en.wikipedia.org/wiki/Project_manager

25. 1. Project Management: Strategic Design \& Implementation, 5th Ed., (2006) David I. Cleland and Lewis R. Ireland 
26. 2. Project Manager's Portable Handbook, 2nd Ed. (2004) David I. Cleland and Lewis R. Ireland

27. http://pmtips.net/project-control/

28. http://www.made4u.info/wp9/

29. http://www.interworks.com/blogs/mmedici/2010/01/29/project-management-how-deal-changes-project

30. http://www.usask.ca/its/services/itproject_services/managing_projects/life_cycle.php 